\title{
THE RF SYSTEM DESIGN FOR THE SPALLATION NEUTRON SOURCE *
}

\author{
D. Rees, M. Lynch, P. Tallerico, W. Roybal, K. Cummings, T. Hardek, J. Bradley, W. Reass, A. \\ Regan, LANL, Los Alamos, NM 87545, USA
}

\begin{abstract}
Spallation Neutron Source (SNS) accelerator includes a nominally $1000 \mathrm{MeV}, 2 \mathrm{~mA}$ average current linac consisting of a radio frequency quadrapole (RFQ), drift tube linac (DTL), coupled cavity linac (CCL), a medium and high beta super conducting (SC) linac, and two buncher cavities for beam transport to the ring. Los Alamos is responsible for the RF systems for all sections of the linac. The SNS linac is a pulsed proton linac and the RF system must support a $1 \mathrm{msec}$ beam pulse at up to a $60 \mathrm{~Hz}$ repetition rate. The RFQ and DTL utilize seven, 2.5 MW klystrons and operate at $402.5 \mathrm{MHz}$. The CCL, SC, and buncher cavities operate at $805 \mathrm{MHz}$. Six, 5 MW klystrons are utilized for the CCL and buncher cavities while eighty-one $550 \mathrm{~kW}$ klystrons are used for the SC cavities. All of the RF hardware for the SNS linac is currently in production. This paper will present details of the RF system-level design as well as specific details of the SNS RF equipment. The design parameters will be discussed. One of the design challenges has been achieving a reasonable cost with the very large number of high-power klystrons. The approaches we used to reduce cost and the resulting design compromises will be discussed.
\end{abstract}

\section{RF SYSTEM DESIGN}

The partitioning of the RF system for the SNS accelerator is illustrated in Fig. 1. The RFQ and DTLs are driven by pulsed $2.5 \mathrm{MW}, 402.5 \mathrm{MHz}$ klystrons. These accelerating structures are followed by four CCL cavities. A single, pulsed, $5 \mathrm{MW}, 805 \mathrm{MHz}$ klystron provides power to each CCL cavity. The power from the klystron is split, and the cavity is driven through two RF windows. The CCL cavities are followed by eighty-one super-conducting (SC) cavities. Each SC cavity is driven by a pulsed $550 \mathrm{~kW}$ klystron.
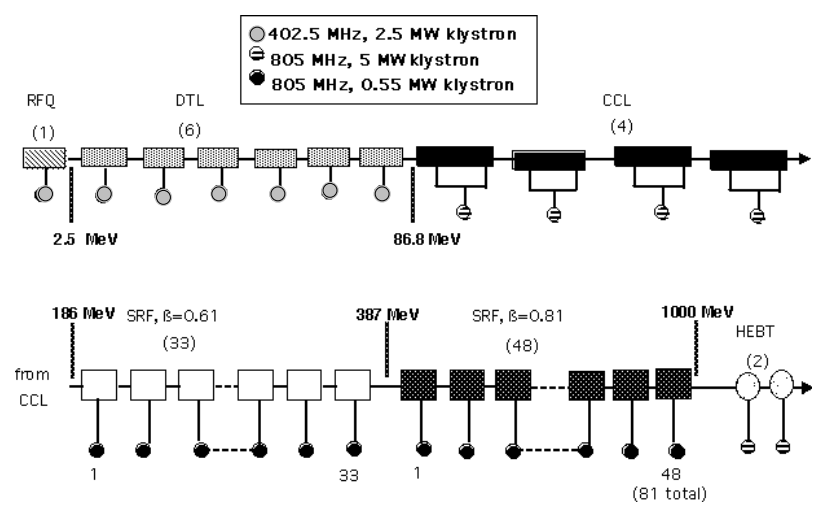

Figure 1: SNS RF system partitioning.

* Work supported by US Department of Energy.
The klystrons are sized to allow at least $25 \%$ power overhead in the room temperature portion, and as much as $40 \%$ in the high beta SC linac for fast cavity field control and transmission and reflection loss. Two variations of a similar power supply design are used for the linac RF systems. The RFQ, DTL, and CCL klystrons utilize a $140 \mathrm{kV}, 90$ A pulsed power supply capable of supplying an average power of $1 \mathrm{MW}$ and a peak power of $11 \mathrm{MW}$. The SC linac uses an $80 \mathrm{kV}, 140$ A pulsed power supply capable of $1 \mathrm{MW}$ of average power and $11 \mathrm{MW}$ of peak power. Because the RF station requirements are well below the klystron rating for the RFQ and first two DTL cavities, one power supply is used to run these three systems. For the remainder of the DTL RF stations, two $2.5 \mathrm{MW}$ klystrons share a single power supply. For the CCL RF stations, one $140 \mathrm{kV}$ power supply is required for each klystron. The first forty-eight $550 \mathrm{~kW}$ klystrons are run at less than maximum power and are fed in groups of twelve from four power supplies. The next thirty-three $550 \mathrm{~kW}$ klystrons are run at close to maximum power are fed in groups of 11 from three power supplies due to the 11 MW peak power.

The SNS klystrons do not have a modulating anode. The klystron gun is a diode gun and the pulsed power supply voltage pulses the klystron beam current and determines the level of the beam current. The klystron parameters are included below in Table 1. Since the cathode voltage determines the beam, the system design must accommodate variations in klystron perveance as well as end-of-life klystron operation. When operating twelve klystrons from a common power supply, the tube with the lowest perveance will set the operating voltage for the entire group of klystrons. Eliminating the modulating anode was motivated by the experience at other laboratories, reducing the cost of the klystron and associated electronics, and improving the RF system availability.

\section{SNS RF EQUIPMENT}

Details of the RF system components are provided below.

\subsection{Klystrons}

The SNS klystrons are supplied by four manufacturers. The specifications of the SNS klystrons are included in Table 1. The 2.5 MW, 402.5 MHz klystrons are supplied by Marconi (formerly EEV). The $5.0 \mathrm{MW}, 805 \mathrm{MHz}$ klystrons are supplied by Thales (formerly Thomson). The $550 \mathrm{~kW}, 805 \mathrm{MHz}$ klystrons are supplied by two manufacturers, CPI (formerly Varian) and Thales. A photograph of the $402.5 \mathrm{MHz}$ klystron during assembly is included in Fig. 2. The klystrons operate in a vertical 
orientation with localized shielding and are mounted to a socket attached to the lid of tank of dielectric oil. They are protected from high reflected power by a circulator. The $805 \mathrm{MHz}$ klystrons have a separate magnet. The $402.5 \mathrm{MHz}$ klystron has an integral magnet. Currently the $402.5 \mathrm{MHz}$ klystron has completed bakeout and is awaiting test. The $805 \mathrm{MHz}$ klystrons are still in the design phase of their development.

Table 1: SNS klystron operating parameters

\begin{tabular}{|l|l|l|l|}
\hline Peak Power & $2500 \mathrm{~kW}$ & $5000 \mathrm{~kW}$ & $550 \mathrm{~kW}$ \\
\hline Test Power & $2750 \mathrm{~kW}$ & $5500 \mathrm{~kW}$ & $605 \mathrm{~kW}$ \\
\hline Frequency & $402.5 \mathrm{MHz}$ & $805 \mathrm{MHz}$ & $805 \mathrm{MHz}$ \\
\hline Duty Factor & $8 \%$ & $8 \%$ & $9 \%$ \\
\hline Efficiency & $58 \%$ & $55 \%$ & $65 \%$ \\
\hline Beam Voltage & $125 \mathrm{kV}$ & $140 \mathrm{kV}$ & $75 \mathrm{kV}$ \\
\hline Bandwidth $(1 \mathrm{~dB})$ & $1.0 \mathrm{MHz}$ & $2.6 \mathrm{MHz}$ & $2.6 \mathrm{MHz}$ \\
\hline Height & $13 \mathrm{ft}$ & $13 \mathrm{ft}$ & $9 \mathrm{ft}$ \\
\hline
\end{tabular}

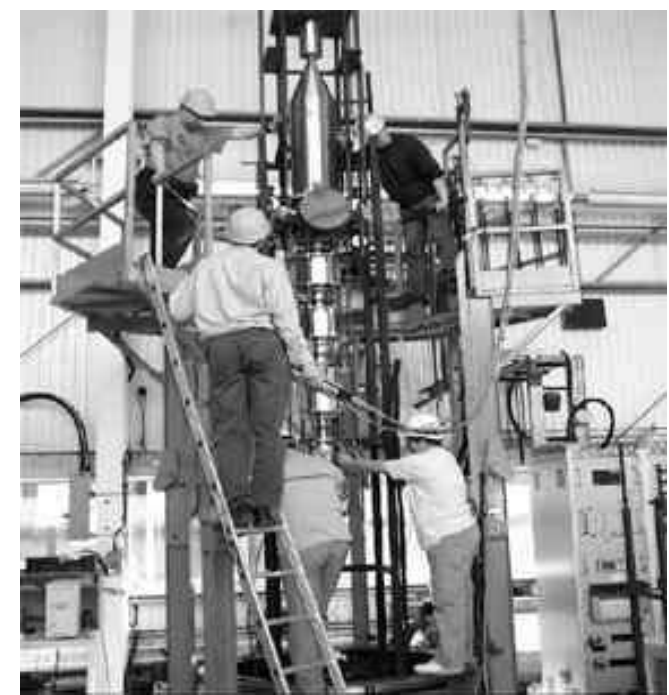

Figure 2: Marconi $402.5 \mathrm{MHz}, 2.5 \mathrm{MW}$ pulsed klystron.

\subsection{Transmitters}

The transmitters in the SNS RF systems comprise the support systems for the klystrons, with the exception of the modulated cathode voltage power supplies. Transmitter sub-systems include:

- water cooling flow control and diagnostics,

- a klystron filament power supply for each klystron,

- klystron magnet power supplies for each klystron,

- a solid state pre-amplifier for each klystron,

- a vac-ion pump power supply,

- oil filled tank(s) for klystron HV connections,

- safety interlocks and equipment interlocks,

- a Programmable Logic Controller (PLC) interface,

- klystron overcurrent diagnostics.

Each of the transmitters for the RFQ, DTL, CCL, and HEBT is designed to support a single $2.5 \mathrm{MW}$ or $5 \mathrm{MW}$ klystron. These transmitters consist of a control rack, a cooling diagnostics cart and a klystron high voltage tank as shown in Fig. 3.

The transmitters for the SC portion of the linac are significantly different. The SC linac design requires many smaller klystrons. Cost and floor space constraints led us to develop a transmitter design capable of supporting six $550 \mathrm{~kW}$ klystrons per transmitter. These transmitters consist of a control rack, a cooling diagnostics cart and two klystron high voltage tanks capable of supporting three klystrons each as shown in Fig. 4.

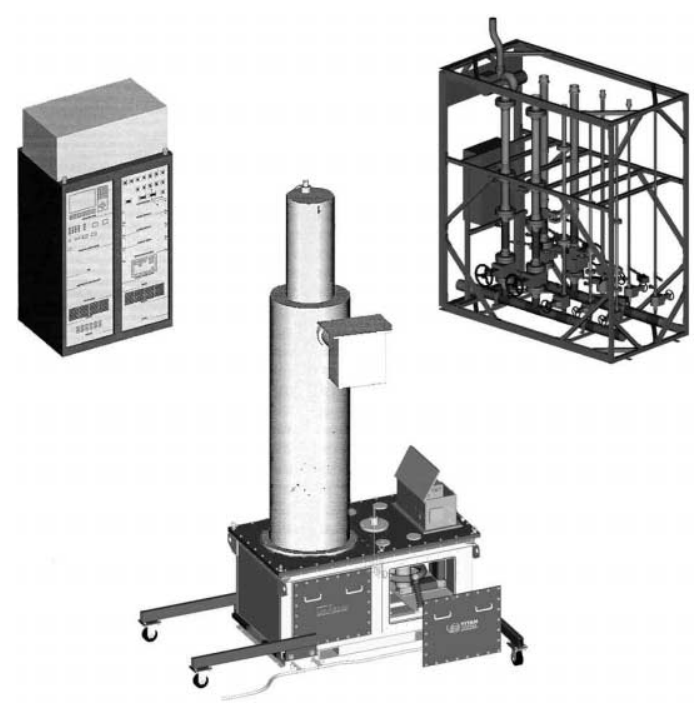

Figure 3: Each transmitter in the normal conducting linac portion support a single $2.5 \mathrm{MW}$ or $5 \mathrm{MW}$ klystron.

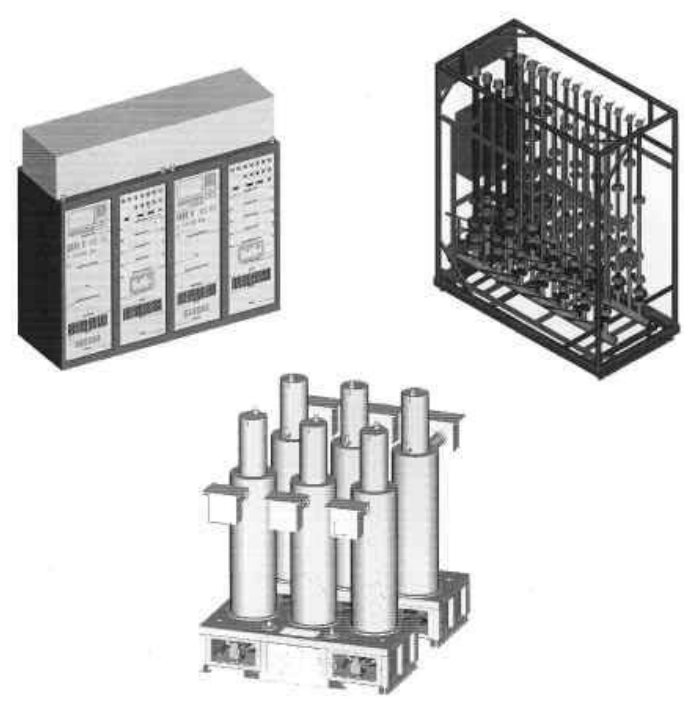

Figure 4: Each transmitter in the SC portion of the linac can support up to six $550 \mathrm{~kW}$ klystrons.

Each of the six klystron sockets have an individual filament transformer, but all six sockets are connected to a single HV connection input. Energy stored in stray capacitance can damage a klystron during a klystron arc. To prevent damage from occurring, the six filament transformers are designed to have a total stray capacitance of less than $1000 \mathrm{pF}$.

Compared to the transmitters in the normal conducting portions of the linac, the footprint of the control rack is only doubled, the footprint of the cooling cart is the same and the footprint of the klystron high voltage tanks is less 
than five times as large. Part of the increase in the number of klystrons supported per unit of floor space and per unit of cost was accomplished by significantly reducing the number and sophistication of the diagnostics and interlocks within the transmitters. For example: transmitters in the SC portion of the linac will monitor only a threshold value of water flow in each cooling circuit, whereas transmitters in the normal conducting portions of the linac will measure and display flow rates, inlet and outlet temperatures and calculate dissipated power in each cooling circuit. Further cost and space reductions were accomplished by providing power to the six klystron ion pumps from a single power supply with a single overcurrent interlock. These changes reduce initial cost at the price of an increase in the effort required to diagnose a faulty klystron.

\subsection{Converter/Modulator Power Supplies}

The converter/modulator power supplies convert the incoming $13.8 \mathrm{kV}$ AC line power to pulsed high voltage DC power suitable for the klystrons. These power supplies are capable of producing up to $11 \mathrm{MW}$ of peak power and $1 \mathrm{MW}$ of average power at a pulse repetition frequency (PRF) of $60 \mathrm{~Hz}$. Two versions of the supply are used to produce the voltages required in Table 1.

The power supplies used with the 2.5 and $5 \mathrm{MW}$ klystrons are capable of producing up to $140 \mathrm{kV}$ and up to 90 A (non simultaneously) with a pulse width of up to 1.2 msec. [1]

The power supplies used with the $550 \mathrm{~kW}$ klystrons are capable of up to $80 \mathrm{kV}$ and up to $140 \mathrm{~A}$ (non simultaneously) with a pulse width of up to $1.3 \mathrm{msec}$.

The prototype $140 \mathrm{kV}$ power supply shown in Fig. 5 has been tested to full peak power and full pulse width. A test of full power operation where the supply delivers the maximum peak power for $1.2 \mathrm{~ms}$ at a $60 \mathrm{~Hz}$ PRF will be conducted after the first $5 \mathrm{MW}$ klystron is delivered to LANL in February of 2002.

\subsection{RF Control}

The RF Control System (RFCS) is required to provide $0.5 \%$ amplitude and $0.5^{\circ}$ phase accuracy of the cavity fields throughout the linac.[2] In order to achieve these control specifications, feedback and feedforward control techniques are incorporated. Other requirements of the RFCS include detection and shutdown of the RF drive to the klystrons should a fault occur in the high power RF transport system. It also performs cavity resonance control and provides for distribution of the phase-stable $\mathrm{RF}$ reference signal at both $402.5 \mathrm{MHz}$ and $805 \mathrm{MHz}$. This is depicted in block diagram form in Fig. 6.

The RF Control System (RFCS) consists of three LANL-designed VXIbus modules. The Clock Distribution Module synchronizes the various system clocks with the RF master oscillator and distributes the timing signals received from the Machine Timing System to the RFCS. The High Power Protect Module provides RF transport fault protection by disabling RF drive for high-reflected power, arcs, etc. The Field and Resonance Control Module performs fast control algorithms, internal diagnostics, supervisory computations, brings in the accelerator signals (e.g., Field Sample, Klystron Forward Signals), translates them into their baseband in-phase and quadrature $(\mathrm{I} / \mathrm{Q})$ components, determines the resonance condition of the cavity, sends an error correction signal to the cavity resonance control system (water cooling for normal conducting and mechanical tuner for superconducting cavity), and implements feed-forward algorithms. The first versions of these modules have been built and are in test.

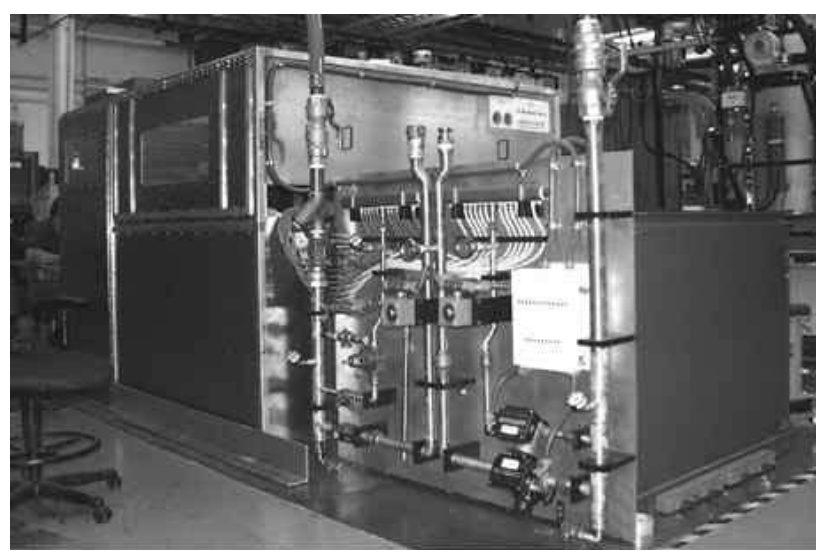

Figure 5: The prototype $140 \mathrm{kV}$ power supply has been tested to full peak power.

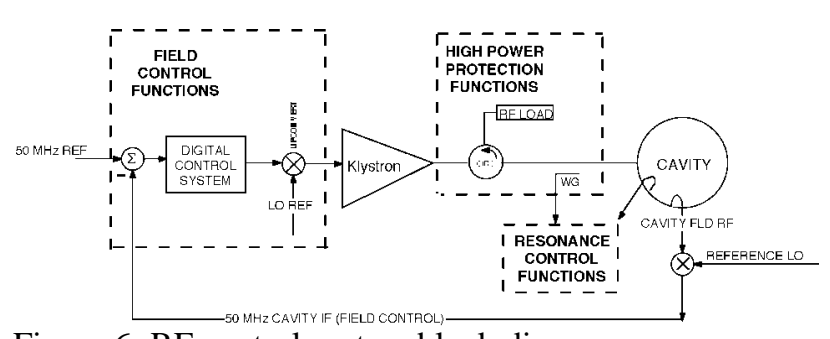

Figure 6: RF control system block diagram.

\section{CONCLUSIONS}

The primary challenge for developing the SNS RF system design was to control cost and size for the large number of systems required for the SC linac. We have presented a design that minimizes footprint and cost without a significant impact on performance and only a modest impact on availability.

\section{REFERENCES}

[1] W. A. Reass, et al, "Operational Results of the Spallation Neutron Source (SNS) Polyphase Converter-Modulator for the $140 \mathrm{KV}$ Klystron RF System," PAC '01, Chicago, June 2001.

[2] A. H. Regan, et al, "The SNS Linac RF Control System,” PAC '01, Chicago, June 2001. 